\title{
Shawan Fish-Lantern Cultural Protection And Development in the View of Cultural Consciousness
}

\author{
Yanling Rang ${ }^{1,2}$ \\ ${ }^{1}$ Anthropology Department , Xiamen University , Xiamen 361000, China; \\ ${ }^{2}$ guangzhou Panyu Polytechnic, Guangzhou 511483, China \\ 809723646@qq.com
}

Keywords: Shawan Fish-Lantern, protection, development

\begin{abstract}
Many local cultural heritage in the process of protection and development Producing cultural commercialization, and the loss of cultural authenticity, have become more and more serious problems. How to protect and develop cultural heritage more effectively, the author believes that these issues need to be guided by Cultural Consciousness Theory. How to protect and develop the fish-lantern culture of Shawan is as an example of prectical study in this paper.
\end{abstract}

\section{Theoretical discussion}

The cultural consciousness theory is proposed by Fei Xiaotong, which refers to the people who live in a certain culture have "self-awareness", understand the origin, the process, the characteristics and the trend of its development. Culture consciousness is not the return, but on the basis of the cultural consciousness, and then carry on the innovation, which makes the culture develop healthily and healthy. [1] The core of the theory is how to understand and reflect on the culture and how to make the culture development sustain. Only cultural consciousness can stimulate the love of this culture, can truly inherit and carry forward the culture.

As for protection, only on the basis of the consciousness of cultural traditions, cultural heritage protection can become conscious behavior. At present, the external force is the main power to promote protection, the internal force is the direction we strive to in the next ten years to twenty years. From the saving protection, productive protection to the cultural ecological protection and then to the full participation of the community on the basis of the cultural consciousness, from the outside to the inside, is the direction of future development of heritage protection.

For development, the author believes that the more backward place's to develop tourism, the more cultural awareness is needed. People only fully understand the value of their own culture, can not imitate, not abandon, and not only to get economic development, but also to not lose its own cultural characteristics, and ultimately stride across to the postindustrial era. Therefore, the author suggests that we should spend great efforts on carding the origin and development, connotation and characteristics of local cultural events, and to attract people to participate in this work. On the basis of this, the local culture education of community residents should be strengthened, and the level of tourism development is consistent with this level, design more tourism activities and tourism lines focusing on experience and interaction, so that visitors and people contact closely, with local cultural connotation.

\section{The fish-lantern culture of Guangzhou Panyu Shawan Town as an example}

Fish- lantern is Shawan ancient folk art. This paper will sort out the origins and development, connotation and the characteristic, current protection and development of Shawan lamp culture. Secongdly on the future development, how to strengthen the local culture of local residents and tourism planning are proposed.

\subsection{Origin and development}

It originally derived from large lanterns at the entrance of the big house. The technological level and size of the lantern often shows prominent degree of the family or the hall. 
He Clan was a prominent family in Shawan since the Song Dynasty. local spread is still a such a two-part allegorical sayings: " Shawan He house (bitter)" (Cantonese "house" with the word "bitter" word homophones). Later it was developed into the "lantern", an parade parts of idolatrous procession, fish-lantern parade, fish-latern drama and so on, and the shapes are not only fish, there are all kinds of animals $\backslash$ fruit shapes, but in order to take "auspicious superabundant" homophonic and collectively referred to as the "fish-lantern".

At the same time, hanging lanterns, blessing to the new newborn a year before in the lunar January in the ancestral hall, is the age-old custom of Shawan. "Lantern" and "ding" homophonic in Chinese, in the ancestral hall lanterns hanging new lamp meaned "add newcomer ". It was in the eighth to sixteenth in lunar January, lantern was written on the name for the newborn son and his father.

\subsection{1 lantern stage}

It was inhabited by a family of He, Li, Wang, Li since the Southern Song Dynasty in Shawan , farming economy and business was very prosperous, temple $\backslash$ houses, the rich mansion row upon row, after nightfall shining everywhere. Lanterns are hung on the porch, under the eaves, written the ancestral hall or the household family surnames, and painted with exquisite painting and calligraphy and traditional craft patterns. For example: Shawan He-Clan ancestral halls was hung a pair of large lanterns in front of the gate, diameter of 1.9 meters, 2.2 meters high, symbolizes the clan of the wealth and power and flourishing.

At the same time, hanging lanterns, blessing to the new newborn a year before in the lunar January in the ancestral hall, is the age-old custom of Shawan. "Lantern" and "ding" homophonic in Chinese, in the ancestral hall lanterns hanging new lamp meaned "add newcomer ". [2] It was in the eighth to sixteenth in lunar January, lantern was written on the name for the newborn son and his father.

\subsection{The stage of an idolatrous procession parade part}

Since the middle of Ming Dynasty, from 1st to 3rd in March every year, Shawan have held a grand festival-the Birth of the North God in the festival. Lanterns are referenced to the idolatrous procession in the queue, and night lighting a small hand-held lanterns, became the shape colorful fish lantern. Before the founding of new China, the annual Lunar New Year on the first day of the first month of the first and August 15, Sha Shi Yufang etc. have special lantern pendulum selling, many people who bought lantern home naturally formed lantern team.

\subsection{Period of fish-lamp parade and fish-lamp drama}

Fish--lantern parade originated from Xinhai Revolution in 1911. In 1912, Shawan people spontaneously held the first large-scale fish--lantern parade to celebrate the victory of the revolution in 1912. In August 1945, to celebrate the victory of the war of resistance against Japan, Shawan masses spontaneously tied many innovative fish--lanterns, with imitations of aeroplanes and warships, goods of different business from various industries. They consciously gathered together in Anning street of Shawan. Over one thousand fish--lanterns formed a spectacular long river of lamps, the long river of joy, to celebrate the victory of the Anti-Japanese War.[3]

Since then, Shawan set October 10 as annual fish--lantern parade day. Large quantities and styles of fish--lanterns have been made by the students in the schools .This activity greatly stimulated the students' imagination and creation.

In 1980, the national day of the people's Republic of China and the Mid-Autumn Festival of the year was the same day, Shawan Town held a grand fish--lantern parade. More than 1000 students from the schools in Shawan tied more than 1000 light lamp. On October 1, 1987, Cultural Bureau and Board of Education in Panyu County called thousands of students to tie thousands of fish-lanterns according to their unique topic, rehearse different models. They held grand fish-lantern performance in Yingdong Stadium in Shiqiao. After that it shifted into silence, until recently.

\subsection{Connotation and characteristics}

The Connotation and characteristics of Shawan fish fish- lanterns reflect in three aspects: symbolizes auspicious meaning; children's entertainment toys; sophisticated technology and rich contents.

\subsection{1 auspicious Symbolization}

Shawan town is located around Panyu rivers and lakes of Pearl River Delta. In the past the river networks interleaved, the villagers lived around water, people has a unique feelings on 
"fish". Shawan fish-lanterns are not all in the shape of a fish, there are all kinds of animals or fruit shape, such as turtle, goldfish, carp, mullet and the white rabbit, lotus and other, but take "more than" homophonic, collectively referred to as " fish- lanterns ", expressed the people hope for a good harvest, good wishes for "auspicious superabundant". At the nights of major festivals , fish- lanterns always enjoy people. Hanging lanterns and watching lanterns when Festival is an indispensable tradition in Shawan folk culture. Every important day, each household will weave or buy fish-lanterns, hanging on the roof or roof,whole family watching them.[4]

\subsection{2 as the children,s entertainment toys}

This is different from other area "Festival Lantern" for Shawan Fish-Lantern . The basic weaving of Shawan Fish-Lantern is easy to grasp, beauty is also easy to show, and they are very popular. daptation to water-nearly habitat environment and utilizing natural easy to get raw materials, bamboo strips, Shawan people developed traditional handicraft industry mainly with woven bamboo products, formed a certain scale of the industry.

In the spare time, people make use of local materials, with bamboo products residual material weaving Fish-Lantern, as children's toys, but also reflects their feelings in the life, production, reflects the strong cultural characteristics of rivers and lakes region.

\subsection{Exquisite workmanship, rich connotation}

Because of the participation of many scholars in the past dynasties, the shape, the workmanship is more sophisticated, the form and content is increasingly rich. Vivid, bright, unique style, ingenious design and beautiful appearance was combined. on the basis of for Fish-Lantern veaving and Fish-Lantern parade, Shawan people have compiled Fish-Lantern theme dance and theatre, performing in the festival and worship.

\section{3 modern protection, heritance and development}

\subsection{Lectures on fish-lanterns and its production}

Due to some historical reasons, the fish-lantens has disappeared for a long period of time in Shawan. In recent years, with the support of Shawan Town Committee and the town government, Shawan fish-lanterns reproduce brilliance. Shawan Town cultural and sports center actively carries out the exploration, protection and inheritance of Shawan fish-lantens.

Through investigation, interviewing with folk artists and folk art research experts, searching the literatures and so on, finally the folk art has been restored. The activities of learning to make fish-lanterns have been held in more than 10 primary and secondary schools in the town of.In November 2011, fish-lantern knowledge lecture was held to teach the younger generation the traditional techniques. Then Making Shawan Fish-lanterns Competition was held, with 1000 teachers, students and parents from more than 30 schools taking an active part in it. They produced more than 350 excellent fish-lantern works.

On the evening of January 3rd, 2012, Shawan Town held 2012 Folk Art Festival by holding various fish-lantern parade activities, such as taking fish-lanterns , singing nursery rhymes, traveling ancient town . Students from kindergartens, primary and secondary schools and their parents attended the festival . Nearly 500 people from 150 families of the parade reproduce the old sight of children carrying fish-lanterns, singing nursery rhymes, touring the ancient town of Shawan.

In March 2012, Shawan Town formally established Shawan Fish-lanterns Association. Members of fish-lanterns artists of the town, folk cultural workers, school teachers and students are to protect and pass on Shawan fish -lantern traditional arts and crafts. The association actively carries out lectures on fish-lanterns knowledge, fish-lanterns copper skill training and other activities. Schools and kindergartens in the town actively hold fish-lanterns making contest, fish-lantern festival, etc. With activities as the carrier, it aims to promote Shawan fish--lantern protection and inheritance work.

\subsection{Participating in the competition and getting a number of honors}

In 2012, in the first Lantern Festival of Guangdong Province, Shawan fish-lantens "Du Zhan Ao Tou" won the gold medal, large fish-lanterns "Yu Yue" and "Long Teng Sheng Shi" won the silver award. The gold medal of "Du Zhan Ao Tou" is made by teachers and students from Shawan Yucai primary school. The work consisted of a male and a female turtle, and production material includes wire, 
bamboo, paper and cloth. The fish-lantern is purely handmade. The fish-lantern "Du Zhan Ao Tou" had bright eyes, the whole body was shining, because it was installed with small flashlight. "Yu Yue" and "Long Teng Sheng Shi" were made by the old artists from Shawan Town Cultural and Sports Center. "Yu Yue" has two jumping fish. While the old tradition is inherited, modern science and technology, electric motors were also applied in the fish so the fish's mouths, fins, tail parts could dance according to the rhythm, which was lifelike and vivid. The "Long Teng Sheng Shi "has two dragons magnificently playing with a pearl, with red and gold as the main color. It presented the auspicious atmosphere, and it also highlighted the features of Shawan fish-lanterns :noble and elegant.

In 2013, In the Second Session of the Lantern Festival of Guangdong Province, with exquisite craftsmanship and profound artistic heritage ,Shawan again won one gold medal(large combining lantern, " Yu Le Sheng Ping "), and a silver medal (large fish-lantern called "ZhuiYue", a large innovative fish-lantern combining tradition and technology); in July 2013, Shawan town won the title of " the lantern countryside of Guangdong Province ".

In the production of "Yu Le Shengping", Shawan Town Cultural and Sports Center and Zhang Zhensheng ,a Shawan fish-lantens artist, closely cooperated. For the difficult problem of " Peacock flaunting its tail", Zhang Zhensheng contemplated for a long time, then thinking a way while drinking tea. Peacock's tail rotates gracefully along with Guangdong music, and majestic dragon takes off around the rocket, with innocent and romantic fishs shine. It won people's woderful praise continuously.

In recent years, Shawan fish- lanterns were also invited to Dongguan, Qingyuan to attend the Province's and different cities'flower-lantern festival, and they are very popular among the local people. For example, in Guangdong International Tourism and Culture Festival Lantern Show in November 2013, Shawan fish- lanterns were also in the show. In the show, Shawan fish- lanterns were dominated by local students'works, which were with fine workmanship, creative and diverse forms. In addition to the traditional fish-lanterns, mechanical elements electronic fish- lanterns are also produced, which were a great feast on the eyes for the visitors.

November 27, 2013, at the Chinese Rural Cultural Tourism Festival and Folk Lantern contest, large fish- lanterns of Shawan called "Tong Xin Hai Yang Meng" won the gold medal with its uniquely creative and exquisite craftsmanship as well as it profound meaning. Thefish-lanterns was themed by adolescents getting together to build the Ocean Dream, made by Shawan fish- lanterns artists and dozens of pupils. The lantern was all handmade, expressing the meaning of self-improvement and struggle for champion.

The lamp set is divided into three layers. The bottom is for "sailing ", the middle layer is for "struggling", and the top is for "achieving", filled with a thick taste of Shawan .The Bottom is in the shape of the island, 100 handmade fish-lanterns made by students from Shawan Xingxian elementary school shuttle in the ups and downs of sea waves, like fish is courageously strive for the best; The middle layer consists of three large alive cod fish lanterns, drawn from the Anti Japanese history during the war period of resistance against Japan when Shawan people spontaneously weaved three cod fish-lanterns dancing in solidarity with the 19th Route Army ,expressing the connotation of the young generaiton's patriotic self-reliance and hard work. On the top ,the champion handed lanterns standing on top of Wenfeng tower (symbolizing the local ancient tower called "Wen Feng")

\subsection{Rendering fish-lantern culture as the characteristic of local schools}

Since 2010, Shawan has launched a series of activities to arrange Lingnan culture to enter into school campus. As for Xingxian Primary School, it is to seek a breakthrough in the development of campus culture by the starting the project of fish-lantern culture. With the deepening of the project, the implied meaning of fish-lanterns is more clear. Fish-lantern means lightning and bright, with lantern getting the meaning of bright. The school hopes that by students' participation in the making of fish-lanterns, students can find the meaning of life and have the passion to pursue good life, so the goal of education is achieved. Also, teachers are on their duty and work as the guiders of students. In 2012 and 2014, the school is reputed as "the Folk Arts Inheritance Base of Fish-Lanterns" by 
Guangzhou City and Guangdong Province respectively, which provides a wider stage for the development of the school cuture.

Xingxian Primary School integrates fish-lantern with "sports and art 2+1" project, taking the production of fish-lanterns as the teaching material in textbook. With more than 1000 teahcers and students, the school divides the course of making fish-lanterns into three levels. Students of lower grades learn to draw simple fish-lanterns. Students of medium grades learn to draw simple skeleton stereogram of fish-lanterns and to make simple ones. As for senior ones, they do creative work while making the fish-lanterns, and Chinese poetry teaching activities are also integrated into this process.

\subsection{Holding intangible cultural heritage exhibition}

On Jan. 15th, Shawan held intangible cultural heritage exhibition in the Youth Activity Center of the town. With rich pictures, videos and easy words, the protection and inheritance of folk arts in Shawan in recent years was displayed. Besides watching the exhibition, people could also participate in the production process, among which fish-lantern making is the most popular.

\subsection{Discussion on the future protection and development}

1. Continuing to deepen community learning and participation of these folk arts, promoting cultural consciousness

As mentioned earlier, fish-lanterns in Shawan once has been ignored for many years, but with recent development, the fish lamp is in full swing now. On Mid-Autumn day, fish lamp production and parade activities are held regularly every year. On Lantern Festival, fish lamp show is held with riddles written on lanterns. However, most of these activities are advocated and planned by the government and cultural institutions, and the folk atmosphere to hold these activities needs to be strengthened. It is recommended to take fish lamp culture as a course. Combing evening classes,community institutions with various Lingnan culture activities in campus togheter, free community educaiton of fish lamp culture is executed by the research results and practical experience.

2.Designing tourist activities and itinerary, advocating traditiaonl folk arts

For example, for pupils, it is suggested to hold fish lamp activities with raw material provied, and pupils are taught how to make fish lamps and they can take the handicrafts home as souvenirs. For the young, first they are invited to appreciate the fish lamps, then they are taught simply how to make them. After that, they are divided into groups and compete with each other to make fish lamps, so that the intercation and exhange among the young can be strengthened. While for the old, nostalgic tour is designed. They are arranged to watch the past video about fish lamp parades, and enjoy students' works of fish lamps.

\section{Acknowledgements}

This is the Guangdong Provincial philosophy and Social Research (Grant No.: GD14XGL20) "cultural heritage protection and development Research based on the cultural consciousness theory -Shawan Town as one of the cases of stage results. ”

\section{References}

[1] Fei Xiaotong, On the Anthropology and Cultural Awareness [M], China Publishers, published in February 2004, p.188

$[2,4]$ Wang Jinqiang, Shawan Fish-Lantern: Brilliance lit the Pearl River Delta (Chinese folk arts and crafts), the overseas edition of the people's Daily Overseas Edition on December 05,2014 , the 15th Edition

[3] Information on http://pyrb.dayoo.com/html/2012-02/12/content_1608731.htm

[5] HuangYanzhu, Charm Shawan Beauty Campus-Shawan Town Lingnan Culture Construction Album of Campus Culture, Guangzhou Panyu District Shawan educational guidance center Compiling,in December 2014 